\title{
The Possibility of Culture: Pleasure and Moral Development in Kant's Aesthetics
}

\section{BRADLEY MURRAY}

JOHN WILEY \& SONS. 2011. 145 PP. £66.95 (HBK).

Recent interpretations of Kant's ethics have tended to foreground its more humane characteristics, stressing the prominence of emotion, habituation and virtue, and distancing us from the harsh and mechanical Kant of legend. ${ }^{1}$ At the same time there has been increasing interest among aestheticians in the moral significance of the aesthetic and in the role it may play in moral development. The Possibility of Culture, a study of the role Kant ascribed to aesthetic experience in fostering the development of moral character, is thus timely and welcome. Murray draws upon texts not traditionally considered in studies of Kant's aesthetics, especially the Anthropology and the Doctrine of Virtue, while placing relatively little emphasis on the well-worked questions surrounding the justification of judgements of taste. Although his book does not always live up to its high promise, it represents nonetheless an important contribution to scholarship on Kant's aesthetics and its place in his wider philosophy.

Murray uses 'culture' in quite a special sense, to outlining which much of Chapter One is devoted. It is not the anthropologists 'culture', the shared practices and values of a community, nor Arnold's 'culture', a canon of artefacts in which the best that has been thought and said is preserved. In fact, it is not necessarily Kant's 'Kultur' either: reference to the original texts reveals that Murray's 'culture' is sometimes translated from 'Kultur' (e.g. CPJ 5:431, quoted at 21) but sometimes from 'Erriebung' (e.g. Pedagogy, 9:452, referenced at 19-20); sometimes too Kant uses 'Kultur' in other contrasting senses (e.g. Pedagogy 9:449, 451, 466). As Murray uses it, culture is 'a developmental process through which we can become more sophisticated moral agents'. According to Kant, this process has four stages: discipline, skill, prudence and finally moralization. Agents act from moral reasons only after moralization, but Murray holds that ascension through the preceding three stages still constitutes moral development, because although agents with discipline, skill and prudence alone do not act from duty, they do act in conformity with it (22-25). Murray's crucial claim is that aesthetic pleasure can bring us this far down the path of culture, though not further: 'pursuing aesthetic pleasure will help us to acquire skill in putting aside our inclinations in order to act in conformity with duty, but will not directly teach us to act from duty. From the Kantian point of view, though, even this is an achievement' (26; cf. 40-41).

Murray discusses three plausible ways in which this can happen. Chapter Two contains a detailed treatment of the role of beauty in fostering love. One's pleasure in beauty is, according to Kant, constituted by the pleasurable feeling 'that the object we find beautiful fits well with our cognitive capacities' (33). The unusual step in Murray's account is the next: drawing on Kant's discussion at (Morals 6:452-453), he claims that this sense of fittingness causes gratitude, because we feel that the object has been made to 'fit exquisitely with our natures' (34). The object of this gratitude is the artist in the case of beautiful artworks: 'it is natural for us to feel gratitude towards [artists who make beautiful works] as we experience the beauty of their artworks' (34); in the case of nature, one's gratitude is felt towards an at least imagined Creator (35). Gratitude in turn causes a desire to do good to one's benefactors, which is both constitutive of love, and a way in which the disposition to love can be strengthened through being exercised (38-9). Although this love is strictly speaking 'pathological', that is, it is an inclination rather than a duty, it tends to cause action that fortuitously conforms with the moral law, and its cultivation accordingly constitutes culture (esp. 39-41).

In Chapter Three Murray considers the idea of disinterestedness: he defends a relatively modest account of what it is for a pleasure to be disinterested, namely that it be 'not fundamentally bound up

1 Hereinafter, the following abbreviations are used: 'CPJ' for the Kritik der Urteilskraft, 'Anthropology' for the Anthropologie in pragmatischer Hinsicht, 'Pedagogy' for the Vorlesung über Pädagogik; 'Morals' for the Metaphysik der Moral. 
with desires we have toward the object' (57). He argues that the disinterestedness of our pleasure in beauty means that we can 'learn through beauty what it is to step back from our inclinations' (57), and in particular that learning how to distance ourselves from our inclinations through feeling disinterested pleasures is a good deal easier and more congenial than learning through repeated self-denial (57-9). Achieving distance from desires is then another step towards acting in conformity with duty. Chapter Four is concerned with Kant's views on art, including discussions of abstraction and genius that must be passed over here. It also includes a third way in which the aesthetic may foster culture, namely through fostering concern for the viewpoints of others. Interestingly Murray thinks that this operates through both the rather dubious concern with whether others view one as a fashionable connoisseur and the more attractive concern with whether others share one's aesthetic judgements (65-70). Both concerns, Murray argues, are ways in which our we 'expand our concern beyond ourselves', and hence they are steps towards the 'universal concern for humanity' that would constitute true virtue (70).

In the book's two remaining chapters Murray discusses Kant's account of the sublime, suggested as a fourth possible way in which aesthetic pleasure might promote culture, and his teleological argument for pursuing culture rather than happiness. Like most commentators he finds these accounts unconvincing $(98-99,114-118)$, and since accordingly they do not play an important role in his positive project, I will not discuss them at length.

There are some oddities of selection here. Kant's claim that beauty is a symbol of the morally good - a claim on which much illuminating work has been done, and of which one would expect to find a substantial treatment in a book-length study of the relationships between the aesthetic and the ethical in Kant - goes unmentioned until the final four pages, where it is discussed only briefly and obliquely (131132). Still more surprisingly, Kant's theory of aesthetic ideas, on account of which he believed that art could 'make sensible' to us the ideas of freedom, God and the immortal soul (CPJ, 5:314), goes wholly unmentioned-another area of great apparent significance to Murray's theme, on which much fine scholarship has been done in recent years. The explanation is perhaps that Murray is concerned specifically with aesthetic pleasure rather than other aesthetic experiences, but it is not clear to me what is gained by this exclusion, which is in any case violated by the inclusion of a chapter on Kant's teleological argument for pursuing culture. This omission is all the stranger given the two chapters Murray devotes to areas in which he finds Kant's views, for largely familiar reasons, wholly unpersuasive. Kant's account of the sublime and his teleological argument for culture are of course intrinsically interesting despite their weaknesses, but given that many eloquent expositions of them exist already, one might have expected those pages to be devoted to proposals that Murray found more promising.

Turning to substantive questions: according to Murray's official characterization of the relationship between culture and aesthetic pleasure in Chapter One, aesthetic pleasure (a) distances us from our inclinations and thereby (b) causes us to act in conformity with-but not from-duty. Curiously however the three relationships Murray goes on to describe each lack one of these characteristics. The first, to recall, was that aesthetic pleasure causes gratitude, which causes 'pathological' love. Love may indeed cause us to act in conformity with the moral law, as per (b), but it is certainly not true that we are thereby distanced from our inclinations, as per (a), since after all pathological love is an inclination. The second was that experiencing aesthetic pleasure habituates a disinterested way of relating to objects. Now this certainly constitutes distancing oneself from one's inclinations, as per (a), but it is unclear whether it is consistent with (b). For (b) to be right, one must be more prone to act, not from duty, but from those inclinations that fortuitously lead to actions that conform with duty. This would require the relative strengthening of those inclinations vis-à-vis inclinations which lead to immoral activity. But what Murray has described is partial liberation from all inclinations, which would leave the relative strengths of our benign and dangerous inclinations unchanged. Curiously, however, it might well make us more likely to act from duty, whose relative appeal vis-à-vis inclination in general would have risen. So (b) 
would be wrong: the acculturating effect of aesthetic pleasure would actually be better than Murray officially claims. The third relationship focussed on the ways that aesthetic experience fosters concern for the viewpoints of others, either because one cares what others think of one's good taste, or because one cares how others judge the object. The first of these certainly involves stimulating inclinations rather than weakening them, and I suspect the second does too: so again, (b) is right and (a) is not. So Murray's official account should be modified: aesthetic pleasure does not necessarily distance us from inclinations, and it may engender either mere conformity to duty or action genuinely from duty.

More seriously perhaps, there is still work to be done to secure gratitude the role that Murray claims for it in mediating between aesthetic pleasure and culture. As Murray claims, 'generally speaking, gratitude is an appropriate response when we feel that we have been given a gift by another', especially 'a gift that has been selected or designed just for us, a gift that suits our personality and nature' (34). It is unclear, however, how often beauty could reasonably occasion this. 'Pure' or 'free' beauty, arguably Kant's paradigm, must be viewed as purposeless. To see the night sky as purely beautiful, we must see it not as 'suns moving in orbits prescribed for them with the wisest regard to ends', but rather 'just as it strikes the eye, as a broad and all-embracing canopy' (CPJ, 5:270). If such beauty must be viewed as purposeless, then a fortiori it must be viewed as not having the purpose of pleasing us: this being so, it is unclear why one should reasonably feel gratitude on account of the object's being or even seeming to be intended to please one. Kant does also write of 'dependent' or 'impure' beauty. How exactly to understand this is much disputed, but such beauty must certainly be seen as having some kind of purpose. Perhaps in the case of natural dependent beauty, where one thinks of the object as designed by nature or God, this might be sufficient for Murray's gratitude, although I am highly unclear that the purpose Kant thinks one must find in natural objects is that of being gifts for oneself. Artistic dependent beauty, by contrast, may well have this purpose, but only in exceptional cases. Vita Sackville-West certainly might have felt grateful to Virginia Woolf upon reading Orlando, the 'longest and most charming love-letter in literature', or Joy Finzi upon listening to her dying husband's musical portrait of her in his Cello Concerto's second movement. But such cases are conspicuously exceptional: in general, it would simply be irrational to believe that artworks were designed as a gift to one. Now there might be ways for Murray to respond to these points: I wondered, for instance, if gratitude for at least dependent beauty might be a 'merely entertained' emotion of the sort which writers like Roger Scruton have discussed, involving seeing the object as having a certain feature without actually believing it to do so. But such work remains to be done.

These objections ought not to distract from the value of The Possibility of Culture. Our understanding of both Kant's ethics and his aesthetics should be enriched by the connections Murray draws between them, and where his account is suggestive rather than conclusive, it is to be hoped that it will provoke further valuable work in the future. 